УДК 624.01.4.046.3:62-192

\title{
РЕЗУЛЬТАТИ СТАТИСТИЧНОГО АНАЛІЗУ МЕТОДІВ РОЗРАХУНКУ ШПОНКОВИХ З'ЄДНАНЬ ТА РЕКОМЕНДАЦІЇ ЩОДО ЇХ ЗАСТОСУВАННЯ
}

Д-р техн. наук В.А. Пашинський, канд. техн. наук О.О. Довженко, магістр В.І. Рудченко РЕЗУЛЬТАТЫ СТАТИСТИЧЕСКОГО АНАЛИЗА МЕТОДОВ РАСЧЕТА
ШПОНОЧНЫХ СТЫКОВ И РЕКОМЕНДАЦИИ ПО ИХ ПРИМЕНЕНИЮ

Д-р техн. наук В.А. Пашинский, канд. техн. наук О.А. Довженко, магистр В.И. Рудченко THE RESULTS OF KEYED JOINTS STATISTICAL ANALYSIS OF DISIGN METHODS AND RECOMMENDATIONS FOR THEIR USING

\section{DSc V. Pashynskyi, PhD O. Dovzhenko, Master student V. Rudchenko \\ Розв'язується питання вибору ефективного методу розрахунку шпонкових стиків. Для порівняння існуючі методи зведено до одного критерію, за допомогою якого здійснено імовірнісний аналіз несучої здатності шпонкових з'єднань. За результатами статистичних обчислень вибрано оптимальний метод розрахунку та надано рекомендації щзодо його застосування.}

Ключові слова: шпонка, метод розрахунку, коефічієнт надійності моделі, імовірнісний аналіз.

Решается вопрос выбора наиболее эффективного метода расчета шпоночных стыков. Для сравнения существующие методы сведены к одному критерию, с помощью которого осуществлен вероятностный анализ несущей способности шпоночных стыков. По результатам статистических вычислений выбран оптимальный метод расчета и даны рекомендации по его применению.

Ключевые слова: шпонка, метод расчета, коэфициент надежности модели, вероятностный анализ.

The question of the choise of the most effective disign keyed joints method is solved. Concrete, reinforced concrete, compressed and reinforced concrete compressed joints were reviewed. For comparison, all the methods are reduced to one criterion by which effected a probabilistic analysis of keyed joints bearing capacity. Reliability coefficient disighn model was used. The main task of any calculation of bilding constructions is providing a sufficient level of reliability and appropriate decision will be correction of disign methods under the same given level of reliability. The table was formed, parameters of it describe the level of reliability and probabilistic errors every of disign methods. All methods were described in original form and after correction on safety factor models for a given reliability. By the results of statistical calculation choose the optimal disign method and gave recommendations on its using.

Keywords: key, disign method, safety factor models, probabilistic analysis.

Вступ. Згідно моніторингового звіту Міністерства регіонального розвитку, будівництва i житлово-комунального господарства показник забезпеченості житлом українців майже вдвічі менше європейського. Враховуючи складне економічне становище в країні, необхідно шукати вигідні й оптимальні шляхи забезпечення населення доступним житлом.
Одним із них $є$ використання технології збірно-монолітного каркасу (ЗМК), котра забезпечує високу якість i швидкість зведення будівель, значне зниження об'єму робіт на будівельному майданчику, зменшення витрат залізобетону на $1 \mathrm{~m}^{2}$ площі будівлі, можливість вільного планування квартир, а тому належить до 
найперспективніших технологій житлового будівництва.

Постановка проблеми у загальному вигляді та іiі зв'язок із важливими науковими та практичними завданнями. Сумісна робота окремих елементів таких будівель часто забезпечується за рахунок шпонкових з'єднань. Наприклад: у житлових будинках на основі конструктивної системи Сарет (рис. 1) і Казань XXI BEK (рис. 2) за допомогою шпонкових стиків сполучають збірні ригелі з колонами, а в системі Аркос (рис. 3) вони забезпечують сумісну роботу багатопустотних плит перекриття із монолітними ригелями та між собою. Вдосконалення методики розрахунку шпонкових з'єднань $є$ актуальною задачею.

Аналіз останніх публікацій. Існуючі методи розрахунку міцності стиків зазвичай базуються на емпіричній основі, $\epsilon$ частковими, мають вузьку галузь застосування, обмежену умовами виконаного досліду, та приводять до результатів, які суттєво відрізняються чисельно. Тому важко віддати перевагу будь-якій із відомих методик.

При випробувані окремих шпонок, дослідники, як правило, фіксують три характерних випадки руйнування зминання, зріз і згин залежно від відношення глибини

до

висоти

шпонки

$l_{k} / h_{k}$.

Проаналізуємо теоретичні залежності для визначення міцності шпонок при зрізі (табл. 1) 3 метою надання рекомендацій щодо можливості їх застосування. Серед факторів, які обумовлюють міцність шпонки, виділяють: характеристики міцності бетону, геометричні параметри стика, рівень обтиснення й армування.

В ПолтНТУ ім. Юрія Кондратюка розроблено варіаційний метод теорії пластичності бетону, який базується на розгляді характеру руйнування шпонок i враховує повну сукупність визначальних факторів міцності [13].

Метою роботи $€$ надання рекомендацій щодо застосування конкретного методу розрахунку міцності шпонкових з'єднань на основі аналізу надійності існуючих методик.

Виклад основного матеріалу i результати. Для порівняльного аналізу існуючих методів розрахунку створена електронна база експериментальних досліджень шпонкових стиків [9], яка включає дані випробувань 91 зразка для чотирьох типів з'єднань, котрі були отримані шістьма авторами: із них 23 бетонних, 29 обтиснутих бетонних, 28 залізобетонних і 11 залізобетонних обтиснутих шпонок.

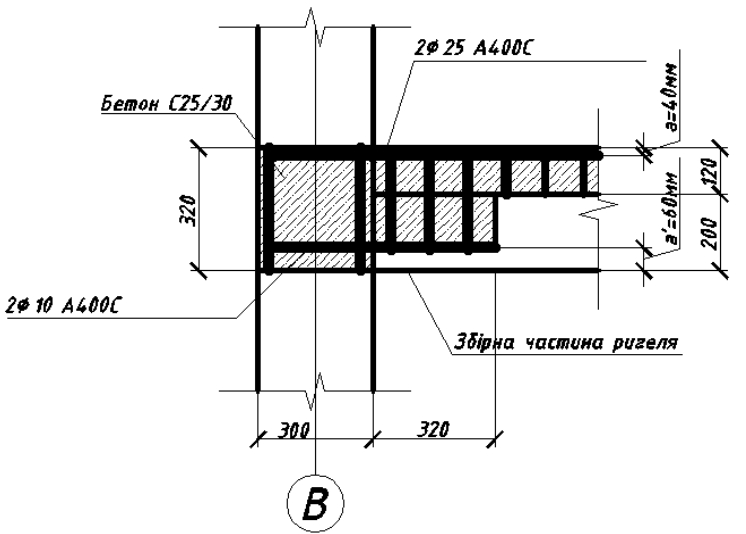

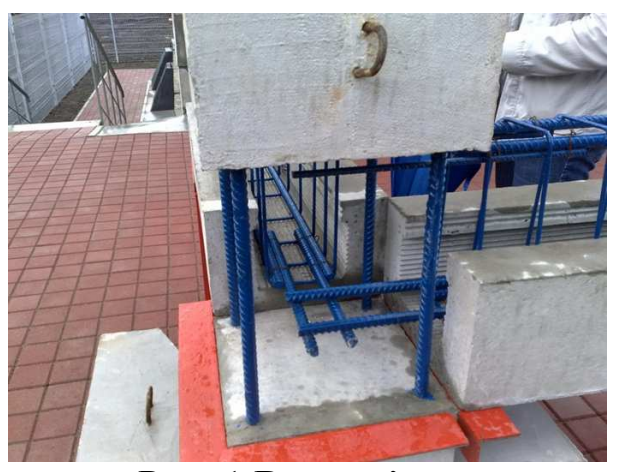

Рис. 1 Вузол з'єднання ригеля з крайньою колоною в ЗМК Сарет
Для кожного виду шпонок наявно більше 10 - ти випробуваних зразків, що допускає виконання статистичного аналізу, а досить широкі межі варіювання основних характеристик забезпечують можливість порівняння результатів випробувань 3 різними розрахунковими методами.
Вихідними даними при цьому являються: $X_{e}$ - експериментальні значення умовних напружень зрізу шпонки; $X_{c}-$ теоретичні середнє значення несучої здатності (обчислені 3 урахуванням середньої міцності бетону); $X_{p}$ - теоретичні розрахункові значення несучої здатності 

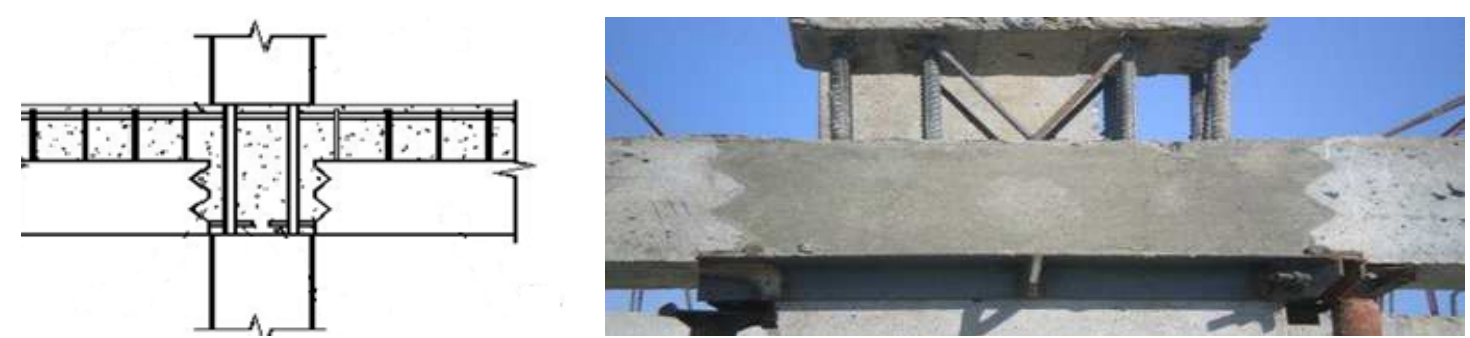

Рис. 2 Шпонковий стик ригеля з колоною в ЗМК Казань XXI ВЕК

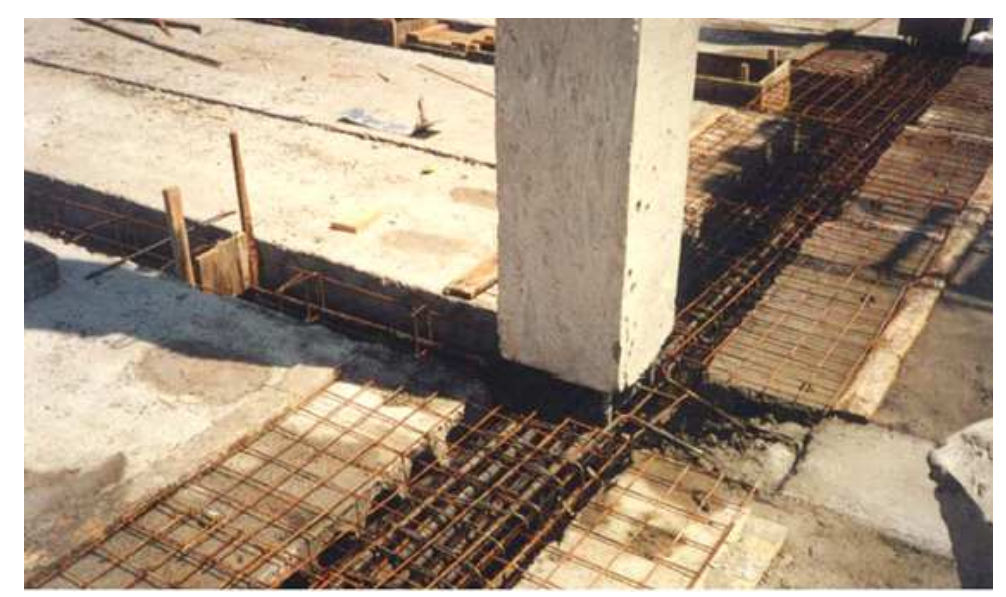

Рис. 3 Вузол сполучення збірних багатопустотних плит з монолітними ригелями в ЗМК Аркос

За наявними даними для кожного зразка та кожного методу розрахунку підраховані відносні відхилення середніх і розрахункових теоретичних значень від експериментальних, а також для кожного виду шпонок та обраного методу розрахунку сформовані вибірки відносних відхилень. Додатні відхилення відповідають небажаній ситуації, коли розрахунковий метод завищує несучу здатність конструкції. Відхилення зі знаком «мінус» означають наявність запасу надійності. Статистична обробка отриманих вибірок виконана за відомою методикою в середовищі MS Excel iз обчисленням середніх значень та стандартів відхилень.

Середне значення характеризує систематичну похибку розрахункового методу, а стандарт - ï випадкову складову.

Забезпеченість результатів розрахунку, тобто показник надійності розрахункового методу, дорівнює імовірності того, що відхилення розрахункових значень будуть від'ємними, тобто обраний метод розрахунку забезпечує запас надійності:

$$
P_{P}=\operatorname{IMOB}\left\{\Delta_{p}<0\right\}
$$

Цю імовірність можна визначити за таблицями нормального розподілу [11] через аргумент:

$$
t_{c}=M_{\Delta C} / S_{\Delta C} \quad\left(t_{p}=M_{\Delta P} / S_{\Delta P}\right),
$$

або безпосередньо через вбудовану функцію нормального розподілу в Excel.

Якщо даний метод розрахунку не має систематичної похибки, то середні відхилення повинні наближатися до нуля $(\Delta c$ $\approx 0$ ), а їх забезпеченість має дорівнювати $P_{C}$ $\approx$ 0,5. Забезпеченість розрахункових відхилень повинна бути досить близькою до одиниці $\left(P_{C} \rightarrow 1\right)$. Це свідчитиме про достатню надійність обраного методу розрахунку.

Якісний, точний i надійний метод розрахунку повинен мати незначну систематичну похибку, досить високий рівень забезпеченості $P_{P}$ та невеликі запаси міцності, які можна оцінити за середнім значенням розрахункових відхилень $M_{\Delta P}$. 
В якості прикладу розглянемо аналіз методу розрахунку міцності бетонних шпонок за ВСН 72-77 [1].

Вибірки експериментальних $X_{e}$ i теоретичних $X_{c}$ i $X_{p}$ значень несучої здатності, а також середніх і розрахункових відхилень $\Delta c$ i $\Delta p$ (1) для 23 дослідних зразків наведені в табл. 2.

Iз результатів статистичної обробки видно, що даний метод розрахунку має систематичну похибку в запас надійності, тобто занижує середню несучу здатність шпонки на 25,5\%. Забезпеченість середніх відхилень при цьому складає $P_{C}=0,945$. Розрахунковий середній запас міцності становить $64,1 \%$, а рівень забезпеченості $P_{P}$ $\approx 1,00$.

Для порівняння різних методів розрахунку доцільно звести їх характеристики до одного критерію, забезпечивши рівність інших характеристик. Для їх варіювання використано коефіцієнт надійності розрахункової моделі $\gamma_{r d}$, можливість врахування якого регламентована нормами [12].

Головним і першочерговим завданням будь-якого розрахунку несучих будівельних конструкцій $\epsilon$ забезпечення достатнього рівня надійності, тому адекватним рішенням буде коригування розрахункових методів для всіх видів шпонок під заданий, однаковий для всіх методів, рівень надійності.

В якості такого значення доцільно прийняти встановлену нормами [12] мінімально допустиму забезпеченість розрахункового опору матеріалів $\mathrm{P}_{p}=0,995$. При рівних показниках надійності розрахунку кращим слід вважати метод, який дає менші запаси несучої здатності, тобто менше значення $\mathrm{M}_{\Delta P}$.

3 використанням надбудови Excel «Пошук рішення» обчислюється таке значення $\gamma_{r d}$, котре забезпечить заданий рівень надійності розрахунку.

3 табл. 3 видно, що при коефіцієнті надійності моделі $\gamma_{r d}=0,551$ отримана забезпеченість результатів розрахунку $\mathrm{P}_{p}=$ 0,995 . Середній запас розрахункових значень несучої здатності у результаті коригування зменшився до $34,7 \%$.

За цією методикою виконано аналіз шести методів розрахунку бетонних $\mathrm{i}$ залізобетонних шпонок, п'яти - обтиснутих бетонних i двох методів розрахунку обтиснутих залізобетонних шпонок. Результати представлені у вигляді діаграм середніх запасів для усіх типів шпонок (рис. 4.)

Iз діаграм видно, що для всіх типів шпонок найнижчі середні запаси міцності після коригування забезпечує варіаційни метод, який i рекомендується до практичного застосування.

Висновки за результатами дослідження.

1. Вибір оптимального методу розрахунку шпонкових з'єднань виконано за результатами статистичного аналізу запасів міцності розрахункових значень несучої здатності відносно експериментальних даних.

2. Порівняльний аналіз методів розрахунку, базується на використанні коефіцієнтів надійності моделі: коригування здійснюється до заданого рівня забезпеченості розрахунку та порівняння середніх запасів.

3. До застосування для розрахунків шпонкових з'єднань усіх видів рекомендується варіаційний метод теорії пластичності, який при обраному рівні надійності 0,995 має найнижчі середні запаси міцності та відповідно мінімальні витрати матеріалів. 
Таблиця 1

Методи розрахунку міцності шпонкових з'єднань

\begin{tabular}{|c|c|c|}
\hline Вид & Розрахункові залежності & Джерело, автор \\
\hline \multirow{5}{*}{ 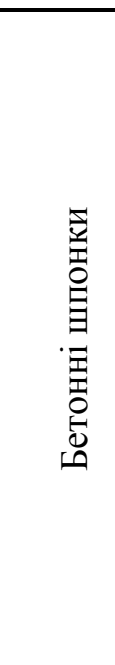 } & 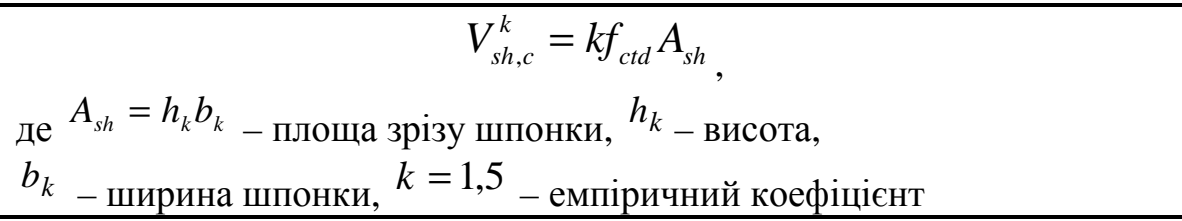 & $\begin{array}{l}\text { ВСН 72-77, } \\
\text { Пособие по } \\
\text { проектированию } \\
\text { жилых зданий }\end{array}$ \\
\hline & $\begin{array}{l}\qquad V_{s h, c}^{k}=c f_{c t d} A_{s h} \leq 0,5 v f_{c d} A_{s h}, \\
\text { де } c-\text { коефіцієнт, для шпонкового профілю } 0,5 ; v-\text { коефіцієнт } \\
\text { зниження міцності }\end{array}$ & $\begin{array}{l}\text { Eurocode } 2, \\
\text { ДСТУ Б В.2.6 }\end{array}$ \\
\hline & $V_{s h, c}^{k}=2 f_{c t d} A_{s h}$ & СП 52-117-2008 \\
\hline & 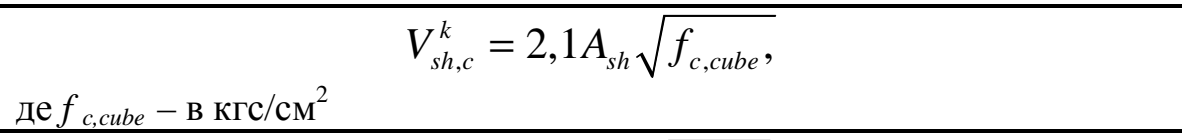 & Рохлін I.А. \\
\hline & $V_{s h, c}^{k}=1,7 A_{s h} \sqrt{f_{c, \text { cube }}}$ & Коноводченко В.I. \\
\hline \multirow{5}{*}{ 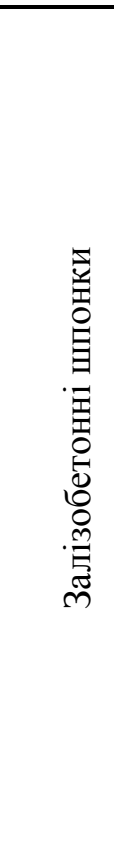 } & $\begin{array}{c}V_{s h, s}=V_{s h, c}^{k}\left(1-f \eta_{\alpha}\right)+f\left(\rho_{s w} f_{y w d}\right) b_{k} h_{k}, \\
\text { але не більше } V_{s h, s}^{\max }=b_{k} h_{k} f_{c t d} \sqrt{f_{c t d}+\rho_{s w} f_{y w d}}, \\
\eta_{\alpha}=\frac{\operatorname{tg} \alpha-f}{1+f \operatorname{tg} \alpha} \geq 0,15 ; \quad f-\text { коефіцієнт тертя (при сейсмічних } \\
\text { де } \\
\text { впливах }-0,5 ; \text { для інших }-0,7) ; \rho_{s w}-\text { коефіціснт армування стику }\end{array}$ & BCH 72-77 \\
\hline & $V_{s h, s}=V_{s h, c}^{k}+0,7 f_{y w d} A_{s w}$ & СП 52-117-2008 \\
\hline & $\begin{aligned} V_{s h, s}=V_{s h, c}^{k}+f\left(f_{y w d} A_{s w}-\eta_{\alpha} V_{s h, c}^{k}\right) \\
f=0,7 \div 0,8 ; \eta_{\alpha}=0,15 \div 0,2\end{aligned}$ & Ашкінадзе Г.I. \\
\hline & $\begin{array}{c}V_{s h, s}=V_{s h, c}^{k}\left(1+410^{-5} f_{y w d} n d\right) \\
\text { де } n, d-\text { кількість i діаметр арматурних стрижнів у стику }\end{array}$ & Коноводченко В.I \\
\hline & $\begin{array}{c}V_{s h, s}=V_{s h, c}^{k}+\rho_{s w} f_{y d} \mu A_{s h} \leq 0,5 v f_{c d} A_{s h}, \\
\text { де } c_{\text {i }} \mu{ }_{- \text {коефіцієнти, котрі залежать від шорсткості поверхні }}\end{array}$ & $\begin{array}{c}\text { ДСТУ Б В.2.6, Eurocode } \\
2\end{array}$ \\
\hline \multirow{4}{*}{ 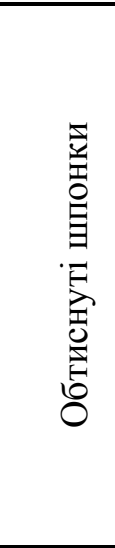 } & $V_{s h, \sigma}^{k}=V_{s h, c}^{k}+0,7 N$ & ВCH 72-77 \\
\hline & $\begin{array}{c}V_{s h, \sigma}^{k}=V_{s h, c}^{k}+\mu N, \\
\text { де }^{\mu=0,9}-\text { коефіцієнт, який залежать від виду поверхні }\end{array}$ & $\begin{array}{l}\text { Eurocode 2, } \\
\text { ДСТУ Б В.2.6 }\end{array}$ \\
\hline & $V_{s h, \sigma}^{k}=0,9 V_{s h, c}^{k}+N$ & $\begin{array}{c}\text { Пособие по } \\
\text { проектированию жилых } \\
\text { зданий } \\
\end{array}$ \\
\hline & 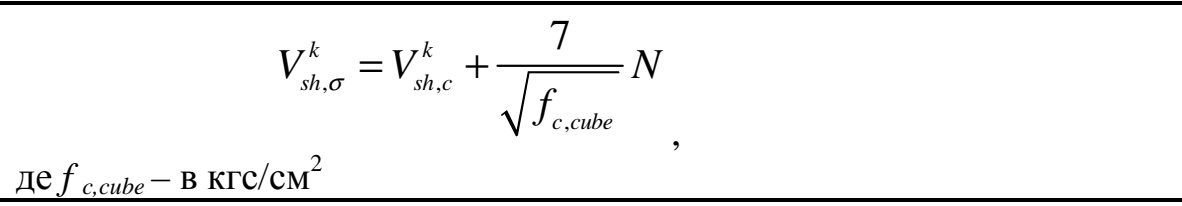 & Рохлін I.A. \\
\hline 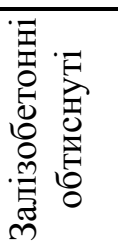 & $\begin{array}{c}V_{s h, \sigma, s}^{k}=c f_{c t d}+\mu \sigma_{n}+\rho_{s w} f_{y d} \mu \leq 0,5 v f_{c d}, \\
\text { де }^{\mu=0,9},{ }^{c=0,5}-\text { коефіцієнти, що залежать від виду поверхні }\end{array}$ & $\begin{array}{l}\text { Eurocode } 2, \\
\text { ДСТУ Б В.2.6 }\end{array}$ \\
\hline
\end{tabular}


Таблиця 2

Порівняння теоретичних та експериментальних значень несучої здатності бетонних шпонок

\begin{tabular}{|c|c|c|c|c|c|}
\hline № & $X e$ & $X c$ & $X p$ & $\Delta c$ & $\Delta p$ \\
\hline 1 & 3,49 & 2,85 & 1,236 & $-0,184$ & $-0,646$ \\
\hline 2 & 3,24 & 2,85 & 1,236 & $-0,120$ & $-0,619$ \\
\hline$\ldots$ & $\ldots$ & $\ldots$ & $\ldots$ & $\ldots$ & $\ldots$ \\
\hline 22 & 3,92 & 2,265 & 1,442 & $-0,422$ & $-0,632$ \\
\hline 23 & 9,01 & 3,975 & 2,814 & $-0,559$ & $-0,688$ \\
\hline \multicolumn{4}{|c|}{$\mathrm{N}=$} & 23 & 23 \\
\hline \multicolumn{4}{|c|}{$M=$} & $-0,255$ & $-0,641$ \\
\hline \multicolumn{4}{|c|}{$S=$} & 0,160 & 0,074 \\
\hline \multicolumn{4}{|c|}{ Забезпеченість Р } & 0,945 & 1,000 \\
\hline
\end{tabular}

Таблиця 3

Відхилення теоретичних значень несучої здатності бетонних шпонок, скоригованої за заданим рівнем надійності

\begin{tabular}{|c|c|c|c|c|c|}
\hline № & $\mathrm{Xe}$ & 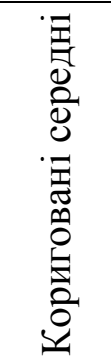 & 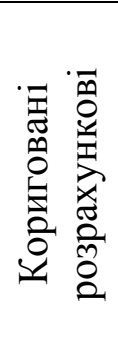 & 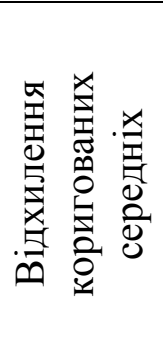 & 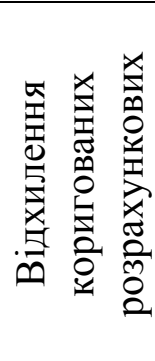 \\
\hline 1 & 3,49 & 5,176 & 2,245 & 0,482 & $-0,357$ \\
\hline 2 & 3,24 & 5,176 & 2,245 & 0,598 & $-0,307$ \\
\hline$\ldots$ & $\ldots$ & $\ldots$ & $\ldots$ & $\ldots$ & $\ldots$ \\
\hline 22 & 3,92 & 4,114 & 2,618 & 0,049 & $-0,332$ \\
\hline 23 & 9,01 & 7,219 & 5,111 & $-0,199$ & $-0,433$ \\
\hline \multicolumn{4}{|c|}{$\mathrm{N}=$} & 23 & 23 \\
\hline \multicolumn{4}{|c|}{$\mathrm{M}=$} & 0,353 & $-0,347$ \\
\hline \multicolumn{4}{|c|}{$\mathrm{S}=$} & 0,290 & 0,135 \\
\hline \multicolumn{4}{|c|}{ Забезпеченість Р } & 0,112 & 0,995 \\
\hline
\end{tabular}


a)

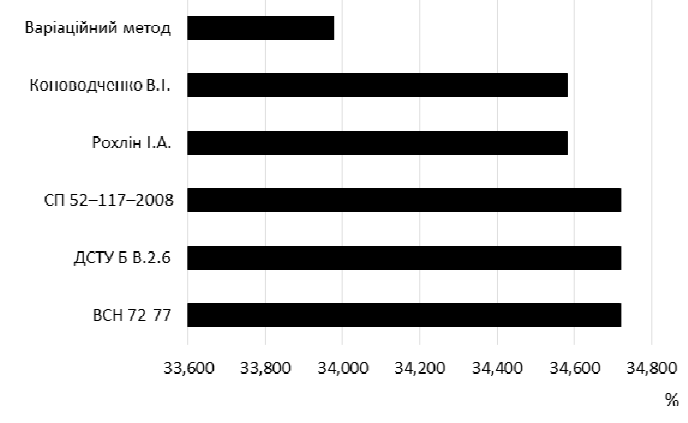

B) б)

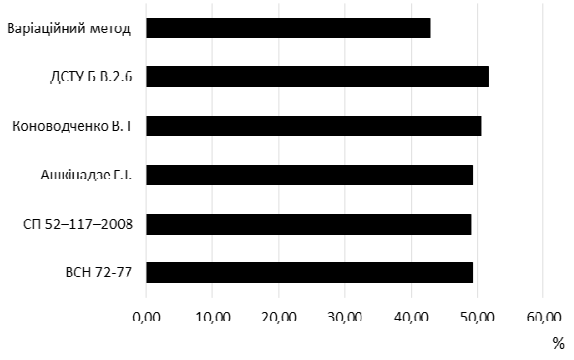

г)
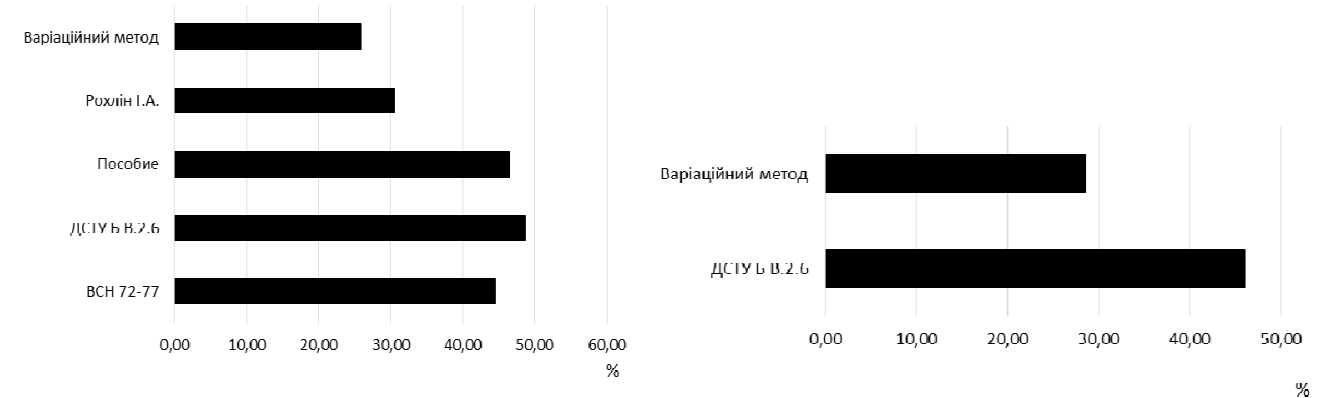

Рис. 4 - Середній запас методів розрахунку при коригуванні за рівнем надійності для: а бетонних; б - залізобетонних; в - обтиснутих; г - залізобетонних обтиснутих шпонок

\section{Список використаних джерел}

1. Инструкция по проектированию конструкций панельных жилых зданий: ВСН 72-77. - М: Стройиздат, 1978. - 177 с.

2. Пособие по проектированию жилых зданий / ЦНИИЭП жилища Госкомархитектуры. Вып. 3. Конструкции жилых зданий (к СНиП 2.08.01-85). - М.: Стройиздат, 1989. - 304 с.

3. Eurocode 2, Part 1. Design of concrete structures. 1992.

4. Бетонні та залізобетонні конструкції з важкого бетону: ДСТУ Б В.2.6. - К.: НДІБК, 2010. - $156 \mathrm{c}$.

5. Железобетонные пространственные конструкции покрытий и перекрытий. Часть 1. Методы расчета и конструирование: СП 52-117-2008. - М., 2008. - 240 с.

6. Рохлин И.А. Исследование и расчет бессварочных шпоночных стыков тонкостенных железобетонных конструкций / И.А. Рохлин, В.А. Бондарев. - К.: НИИСК Госстроя СССР, 1968. - 34 c.

7. Коноводченко В.И. Прочность стыковых соединений сейсмостойких крупнопанельных зданий при сдвиге / В.И. Коноводченко, А.В. Черкашин, П.Н. Бобришев // Бетон и железобетон. - 1968, - №8. - С. 5 - 12.

8. Ашкинадзе Г.Н. Использование каркасно-стержневой модели в исследовании работы шпоночных стыков на сдвиг конструкций / Г.Н.Ашкинадзе, И. Л. Герасимова // Прочность и трещиностойкость коротких железобетонных элементов: межвуз. сб. - Казань: КИСИ, 1989. - C. $35-41$.

9. Пашинський В. А. Результати статистичного аналізу методів розрахунку шпонкових 3'єднань та рекомендації щодо їх застосування / В. А. Пашинський, О. О. Довженко, В. І. Рудченко // Матеріали Всеукраїнської інтернет-конференції молодих учених і студентів «Проблеми і перспективи сталого розвитку та просторового планування територій» 18 бер. 2015 р. [Текст]. - Полтава: ПолтНТУ ім. Ю. Кондратюка, 2015. - 305 с.

10. Пашинський В. А. Методика статистичного аналізу точності та ефективності розрахунківшпонкових з’єднань / В. А. Пашинський, О.О. Довженко, В. І. Рудченко // 
Ресурсоекономні матеріали, конструкції, будівлі та споруди: зб. наук. праць. - Рівне: НУВГП, 2015. - Вип. 30. - С. 211-218.

11. Вентцель Е.С. Теория вероятностей / Е.С. Вентцель. - М.: Наука, 1969. - 576 с.

12. ДБН В.1.2-14-2009. Система забезпечення надійності та безпеки будівельних об'єктів. Загальні принципи забезпечення надійності та конструктивної безпеки будівель, споруд, будівельних конструкцій та основ. - Мінбуд України, 2009.

13. Довженко О. О. Методика розрахунку шпонкових з'єднань залізобетонних елементів // О.О. Довженко, В. В. Погрібний, Ю.В. Чурса // Вісник національного університету «Львівська політехніка» «Теорія і практика будівництва» - Львів, 2013. - №755. - C. $111-117$. $86-91$

Пашинський В. А., д. т. н., професор (Кіровоградський національний технічний університет), (099) 735-

Довженко О. О., к. т. н., доцент (Полтавський національний технічний університет імені Юрія Кондратюка), (050) 9825854

Рудченко В. І., магістр (Полтавський національний технічний університет імені Юрія Кондратюка), lerunka1993@gmail.com, (066)6920086 $86-91$

V. Pashynskyi, Professor, Doctor of Technical Science (Kirovograd National Technical University) (099) 735-

O. Dovzhenko, Ph. D. Associate Professor, Docent (Poltava National Technical Yuri Kondratyuk University), (050) 9825854

V. Rudchenko, master student, (Poltava National Technical Yuri Kondratyuk University), lerunka1993@gmail.com, (066)6920086

Стаття прийнята 03.07.2015 p 